\title{
The esoteric roles of Bcl-2 family proteins in glucose homeostasis and cell survival
}

\author{
S Pfeiffer ${ }^{1}$ and JHM Prehn ${ }^{* 1}$ \\ Cell Death and Disease (2015) 6, e1968; doi:10.1038/cddis.2015.320; published online 5 November 2015
}

The prevalence and the incidence of type 2 diabetes mellitus (T2DM) are increasing and now attaining epidemic proportions worldwide. Apoptotic cell death is a hallmark of pancreatic betacell loss not only in type 1 diabetes mellitus (T1DM) but also in all forms of diabetes mellitus, contributing to the development of clinically overt disease. ${ }^{1,2}$ Although activation of pro-apoptotic Bcl-2 protein family members Bax, Bim, Puma and Bad has been identified to initiate beta-cell apoptosis in in vitro and in vivo, ${ }^{3-5}$ recent years have seen the gradual elucidation of additional roles played by Bcl-2 family proteins in the control of beta-cell energetics and glucose-stimulated insulin secretion, indicative of a role for Bcl-2 proteins in beta-cell physiology. ${ }^{6-8}$

In a recent study published in Cell Death Discovery, ${ }^{9}$ we not only demonstrate a role for pro-apoptotic Bcl-2 homology domain-3-only protein Bmf (Bcl-2-modifying factor) as a mediator of beta-cell apoptosis in a mouse model of a monogenic form of diabetes, HNF1a-MODY, but also reveal an extracurricular role for $\mathrm{Bmf}$ in beta-cell insulin secretion unrelated to cell death initiation in vivo (Figure 1). Hepatocyte nuclear factor-1A maturity-onset diabetes of the young (HNF1a-MODY) is the most common monogenic form of diabetes and is characterized by a primary $\beta$-cell failure without features of insulin resistance. The study follows on from previous work demonstrating an AMP-activated protein kinase (AMPK)-dependent induction of Bmf expression during energetic stress in insulin-secreting cells and in the islets of transgenic mice expressing a dominant-negative (DN) mutant of the transcription factor HNF-1 $a$ in beta cells, identifying Bmf as a primary mediator of beta-cell apoptosis in HNF1a-MODY. ${ }^{10}$ Through the introduction of bmf-deficiency in a transgenic HNF1a-MODY mouse model, we report an attenuation in beta-cell loss and preserved insulin content in bmf-deficient diabetic mice. Intriguingly, bmfdeficiency was found to exacerbate rather than reduce hyperglycemia and ultimately resulted in a decreased glucosestimulated insulin response, implicating a role for Bmf in glucose homeostasis regulation in addition to effects on beta-cell survival. Indeed, a decreased glucose-stimulated insulin response was also observed in bmf-deficient non-MODY control mice.

This work expands on current re-thinking of the roles of Bcl-2 family proteins and their functional involvement in physiological pathways other than cell death and survival. ${ }^{11}$ Regulation of cellular metabolic functions in addition to regulation of apoptosis in beta cells has previously been

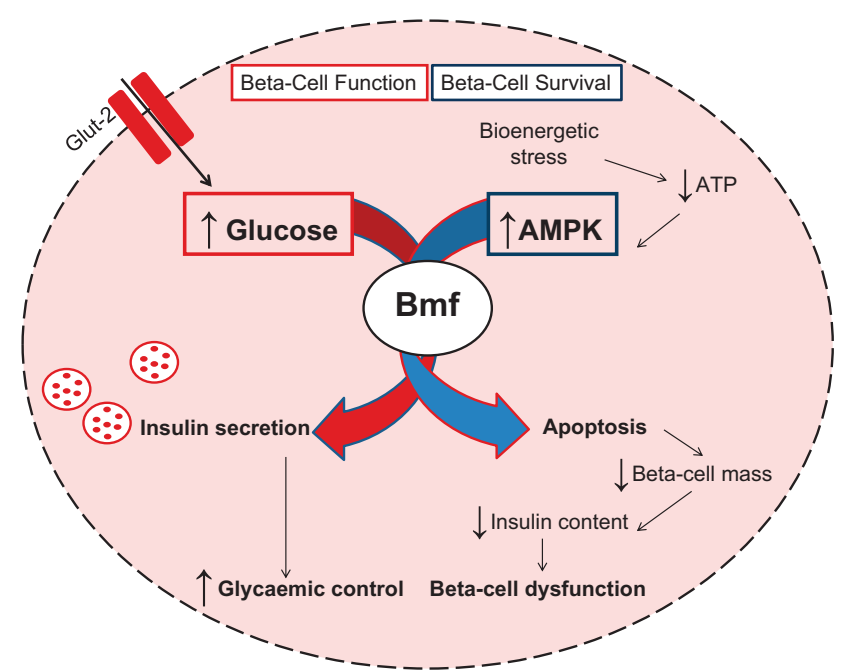

Figure 1 The dual roles for pro-apoptotic Bcl-2 homology domain-3-only protein $\mathrm{Bmf}$ (Bcl-2-modifying factor) as a mediator of beta-cell apoptosis and beta-cell insulin secretion in vivo: Bmf is required for glucose-stimulated insulin secretion in vivo, thereby maintaining glycemic control (red arrow). Depletion of ATP and prolonged activation of AMPK, however, also triggers Bmf-mediated apoptosis of beta cells, resulting in decreased beta-cell mass and corresponding reduction in islet insulin content (blue arrow)

observed in the case of the BH3-only protein Bad, which regulates mitochondrial associated glucokinase activity and mitochondrial respiration in beta cells. ${ }^{7}$ Anti-apoptotic $\mathrm{Bcl}-2$ family proteins $\mathrm{Bcl}-2$ and $\mathrm{Bcl}-\mathrm{xl}$ have also been shown to impact on mitochondrial nutrient metabolism and insulin secretion signaling by dampening the beta-cell response to glucose. ${ }^{6}$ This was observed in the absence of Bax and Bak expression (indicating these were independent of apoptosis signaling), and was attributed to effects of $\mathrm{Bcl}-\mathrm{xL}$ and $\mathrm{Bcl}-2$ on $\mathrm{ER}$ and $\mathrm{Ca}^{2+}$ homeostasis. As both $\mathrm{BCl}-2$ and $\mathrm{Bcl}-\mathrm{xL}$ regulate mitochondrial fusion, effects of $\mathrm{Bcl}-2$ and $\mathrm{Bcl}-\mathrm{xL}$ on mitochondrial morphology, bioenergetics or quality control could have likewise contributed. Bmf is capable of binding $\mathrm{Bcl}-2$ and $\mathrm{Bcl}-\mathrm{xL} .{ }^{12}$ In accordance with the observations of the Johnson group, we demonstrate an impairment of glucose-stimulated insulin secretion in bmf-deficient mice, and a resultant aggravated hyperglycemia that was evident not only in HNF1a-MODY mice but also in the control mice generated 
through a rigorous backcrossing strategy. Although the rat insulin promoter (RIP) system targeted DNHNF-1 a expression to beta cells (and potentially other areas of the brain in which HNF1 $a$ is not highly expressed), it should be noted that the bmf knockout in this model resulted in gene deficiency in all tissues potentially impacting on glucoregulation.

Interestingly, female mice in this model do not manifest the same overt diabetic phenotype as male mice. The sexual dimorphism observed in this model has been paralleled in many other models of diabetes. ${ }^{13}$ Activation of estrogen receptors in rodent models of T1DM and T2DM has been shown to promote $\beta$-cell survival, indicating that the hormonal profile of female animals appears to confer protection from the development of overt diabetes. ${ }^{13,14}$ Interestingly, female mice, that is, MODY mice were protected from beta-cell loss, but were unprotected from loss of glucose-stimulated insulin secretion upon deletion of $b m f$.

Taken together, the results of this study conclude that deletion of bmf results in a rescue of the progressive beta-cell death in a mouse model of monogenic diabetes, but surprisingly also plays a role in glucose homeostasis with an observable insulin secretory defect in vivo. This work provides an insight into the 'day-night' dual role played by $\mathrm{Bmf}$ and other BH3-only proteins in the control of in vivo glucose homeostasis.

\section{Conflict of Interest}

The authors declare no conflict of interest.

1. Butler AE et al. Diabetes 2003; 52: 102-110.

2. Gurzov EN, Eizirik DL. Trends Cell Biol 2011; 21: 424-431.

3. Federici M et al. Diabetes 2001; 50: 1290-1301.

4. McKenzie MD et al. Diabetes 2010; 59: 644-652.

5. Ren D et al. Diabetes 2014; 63: 2744-2750.

6. Luciani DS et al. Diabetes 2013; 62(1): 170-182.

7. Danial NN et al. Nat Med 2008; 14: 144-153.

8. Zhou YP et al. Am J Physiol Endocrinol Metab 2000; 278: E340-E351.

9. Pfeiffer S et al. Cell Death Discov 2015; 1: 15041.

10. Kilbride SM et al. J Biol Chem 2010; 285: 36199-36206.

11. Kilbride SM et al. Oncogene 2013; 32: 2703-2711.

12. Puthalakath $\mathrm{H}$ et al. Science 2001; 293: 1829-1832.

13. Tiano JP et al. Nat Rev Endocrinol 2012; 8: 342-351.

14. Efrat S. Endocrinology 1991; 128: 897-901.

(c) (i) Cell Death and Disease is an open-access journal published by Nature Publishing Group. This work is licensed under a Creative Commons Attribution 4.0 International License. The images or other third party material in this article are included in the article's Creative Commons license, unless indicated otherwise in the credit line; if the material is not included under the Creative Commons license, users will need to obtain permission from the license holder to reproduce the material. To view a copy of this license, visit http://creativecommons.org/licenses/by/4.0/ 